\title{
Reevaluating the Role of Megalin in Renal Vitamin D Homeostasis Using a Human Cell-Derived Microphysiological System
}

\author{
Brian D. Chapron 1, Alenka Chapron 1, Brian Phillips 1, Miracle C. Okoli 1, Danny D. Shen 1, \\ Edward J. Kelly ${ }^{1}$, Jonathan Himmelfarb ${ }^{2}$ and Kenneth E. Thummel ${ }^{1}$ \\ ${ }^{1}$ Department of Pharmaceutics, University of Washington, Seattle, WA, USA; ${ }^{2}$ Department of Medicine, University of Washington, Seattle, WA, USA
}

\begin{abstract}
The role of megalin in the regulation of renal vitamin $D$ homeostasis has previously been evaluated in megalin-knockout mice and rat proximal tubule epithelial cells. We revisited these hypotheses that were previously tested solely in rodent models, this time using a 3-dimensional proximal tubule microphysiological system incorporating primary human proximal tubule epithelial cells. Using this human cell-derived model, we confirmed that $25 \mathrm{OHD}_{3}$ is transported into the human proximal tubule epithelium via megalin-mediated endocytosis while bound to vitamin $D$ binding protein. Building upon these findings, we then evaluated the role of megalin in modulating the cellular uptake and biological activity of $1 \mathrm{a}, 25(\mathrm{OH})_{2} \mathrm{D}_{3}$. Inhibition of megalin function decreased the $1 \mathrm{a}, 25(\mathrm{OH})_{2} \mathrm{D}_{3}$-mediated induction of both cytochrome $\mathrm{P} 45024 \mathrm{~A} 1$ protein levels and 24 -hydroxylation activity following perfusion with vitamin $\mathrm{D}$ binding protein and $1 a, 25(O H)_{2} D_{3}$. The potential for reciprocal effects from $1 a, 25(O H)_{2} D_{3}$ on megalin expression were also tested. Contrary to previously published observations from rat proximal tubule epithelial cells, $1 \mathrm{a}, 25(\mathrm{OH})_{2} \mathrm{D}_{3}$ did not induce megalin gene expression, thus highlighting the potential for meaningful interspecies differences in the homeostatic regulation of megalin in rodents and humans. These findings challenge a recently promoted hypothesis, predicated on the rodent cell data, that attempts to connect $1 a, 25(\mathrm{OH})_{2} \mathrm{D}_{3}$-mediated regulation of renal megalin expression and the pathology of chronic kidney disease in humans. In addition to providing specific insights related to the importance of renal megalin in vitamin D homeostasis, these results constitute a proof-of-concept that human-derived microphysiological systems are a suitable replacement for animal models for quantitative pharmacology and physiology research.
\end{abstract}

\section{Introduction}

In humans, conversion of $25 \mathrm{OHD}_{3}$ to its bioactive form, $1 \alpha, 25(\mathrm{OH})_{2} \mathrm{D}_{3}$, occurs primarily in the renal proximal tubule. It is a tightly regulated process, controlled by a number of intracrine and endocrine feedback loops (Wang et al., 2015; Dusso et al., 2005; Maiti and Beckman, 2007; Perwad et al., 2007). When levels of calcium are low, parathyroid hormone, a potent inducer of renal cytochrome P450 27B1 (CYP27B1), is released from the parathyroid gland to increase production of $1 \alpha, 25(\mathrm{OH})_{2} \mathrm{D}_{3}$ in the kidneys (Dusso et al., 2005; Brenza et al., 1998). When systemic concentrations of $1 \alpha, 25(\mathrm{OH})_{2} \mathrm{D}_{3}$ are elevated, vitamin $\mathrm{D}$ receptor (VDR)-dependent induction of renal cytochrome P450 24A1 (CYP24A1), the 24-hydroxylase responsible for the metabolic inactivation of $1 \alpha, 25(\mathrm{OH})_{2} \mathrm{D}_{3}$ and $25 \mathrm{OHD}_{3}$, acts to reduce $1 \alpha, 25(\mathrm{OH})_{2} \mathrm{D}_{3}$ and maintain mineral homeostasis (Jones et al., 2012).

In order for the proximal tubule epithelial cells (PTECs) to sense and respond to systemic demands for more or less $1 \alpha, 25(\mathrm{OH})_{2} \mathrm{D}_{3}$, both $1 \alpha, 25(\mathrm{OH})_{2} \mathrm{D}_{3}$ and its metabolic precursor, $25 \mathrm{OHD}_{3}$, must gain intracellular access. Both $1 \alpha, 25(\mathrm{OH})_{2} \mathrm{D}_{3}$ and $25 \mathrm{OHD}_{3}$ circulate tightly bound to vitamin D binding protein (DBP) (Bikle et al., 1985, 1986). As a result, passive permeability of the unbound hormone and prohormone alone would yield low unbound intracellular concentrations (Dusso et al., 2005). Nykjaer et al. (1999) conducted a series of experiments in megalin-knockout mice and reported that the major route by which $25 \mathrm{OHD}_{3}$ accesses murine PTECs is via megalin-mediated endocytosis of the DBP-bound 
prohormone from the glomerular ultrafiltrate. Around the same time as these knockout mouse studies were being conducted, Liu et al. (1998) reported that $1 \alpha, 25(\mathrm{OH})_{2} \mathrm{D}_{3}$ induced megalin expression in immortalized rat PTECs.

Taken together, the separate findings of Nykjaer et al. (1999) and Liu et al. (1998) suggested a role for megalin in the physiological maintenance of vitamin D homeostasis, both in health and disease. If $1 \alpha, 25(\mathrm{OH})_{2} \mathrm{D}_{3}$ promotes megalin expression, and if megalin is essential for the renal delivery of $25 \mathrm{OHD}_{3}$, then diminished renal $1 \alpha, 25(\mathrm{OH})_{2} \mathrm{D}_{3}$ synthesis, such as in chronic kidney disease (CKD) (Bosworth and de Boer, 2013), would reduce renal access of $25 \mathrm{OHD}_{3}$ and result in further reductions in $1 \alpha, 25(\mathrm{OH})_{2} \mathrm{D}_{3}$ synthesis and progressively deteriorating vitamin $\mathrm{D}$ status. Predicated solely on rat cell data, this hypothesis of positive feedback has been promoted in a number of reviews (Dusso et al., 2011; Dusso, 2011; Kim and Kim, 2014). However, no follow-up studies evaluating the relationship between $1 \alpha, 25(\mathrm{OH})_{2} \mathrm{D}_{3}$ and megalin expression in a more human-relevant system have thus far been conducted to verify this hypothesis.

Given known interspecies differences in the functionality of megalin-associated proteins, such as cubilin, that support megalin-mediated uptake of DBP (Amsellem et al., 2010; Nielsen et al., 2016; Nykjaer et al., 2001), a move away from animal models to experimental human studies is critical. However, this transition has long been hindered by the lack of a feasible and ethical means of delivering and sampling from an isolated human proximal tubule in vivo. The recent development of a perfusion-based 3-dimensional proximal tubule microphysiological system (PT-MPS) that recapitulates the physiological functions of the renal proximal tubule now permits further exploration of the role of megalin in the regulation of systemic vitamin D homeostasis (Weber et al., 2016). Observations of fluid sheer stress promoting endocytosis and cellular polarization suggest an advantage to studying endocytotic processes in perfusion-based systems (Raghavan et al., 2014; Raghavan and Weisz, 2015). Indeed, retention of microvilli, the subcellular structures upon which functional (i.e., capable of binding extracellular ligands) megalin protein is localized, have been confirmed in the apical membranes of PTECs cultured in the PT-MPS (Weber et al., 2016; Sun et al., 2017). Importantly, the specific design of the PT-MPS permits the delivery of ligands of interest selectively to these apical cell surfaces, facilitating the functional characterization of megalin, a protein that is primarily localized to the apical membrane of PTECs (Kerjaschki et al., 1984).

Using the in vivo-like environment of the PT-MPS and conventional 2-dimensional human PTEC cultures, we tested the hypotheses that (1) megalin modulates the intracellular disposition of DBP-bound vitamin D metabolites, (2) megalin-mediated processes modulate the physiological activity of $1 \alpha, 25(\mathrm{OH})_{2} \mathrm{D}_{3}$, and (3) megalin gene expression is a target for reciprocal regulation by $1 \alpha, 25(\mathrm{OH})_{2} \mathrm{D}_{3}$ in the proximal tubule.

\section{Materials and methods}

\section{Chemicals and reagents}

Bovine serum albumin, hydrocortisone, Tween-20, and Triton X-100 were purchased from Sigma-Aldrich (St. Louis, MO). D-Sucrose was obtained from Fisher Scientific (Itasca, IL). 16\% Formaldehyde (methanol free) was purchased from Polysciences (Warrington, PA). Vitamin D metabolites were obtained from Toronto Research Chemicals (Toronto, Ontario). Dulbecco's phosphate-buffered saline with (DPBS) and without $\left(\mathrm{DPBS}^{++}\right)$calcium and magnesium, 50:50 Dulbecco's modified Eagle's medium with Ham's F-12 (DMEM/F12), Hank's balanced salt solution, penicillin-streptomycin-amphotericin $\mathrm{B}$, insulin-transferrin-selenium A solution (ITS-A), TRIzol ${ }^{\circledR}$ reagent, High Capacity cDNA Reverse Transcription Kit with RNase Inhibitor, TaqMan gene expression assays, fetal bovine serum (FBS), trypsin ethylenediamine tetraacetic acid (EDTA), collagenase type IV, ProLong Gold ${ }^{\circledR}$ Antifade reagent with/without 4',6-diamidino-2-phenylindole (DAPI), and rabbit anti-human CYP24A1 antibody were obtained from Thermo-Fisher (Waltham, MA). Mixed type human vitamin D binding protein (DBP) was purchased from Athens Research \& Technology (Athens, GA). Alexa Fluor 594 conjugated donkey anti-mouse IgG, Alexa Fluor 488 conjugated donkey anti-rabbit IgG, Alexa Fluor 488 conjugated donkey anti-goat IgG, rabbit anti-megalin and mouse anti-sodium-potassium ATPase antibodies were purchased from Abcam (Cambridge, MA). Microfluidic platforms were obtained from Nortis (Woodinville, WA). Human receptor-associated protein (RAP) was purchased from Innovative Research (Novi, MI). Non-pepsinized rat tail collagen I was purchased from Ibidi (Martinsried, Germany). Collagen IV, Matrigel ${ }^{\circledR}$, Transwell ${ }^{\circledR}$ inserts and tissue culture-treated 6-well plates were obtained from Corning (Corning, NY).

\section{Cell culture}

Healthy resections of human kidney cortical tissue were obtained during the surgical removal of renal cell carcinomas at the University of Washington Medical Center. The protocol was approved by the University of Washington Human Subjects Institutional Review Board (protocol \# STUDY00001297). Human PTECs were isolated from kidney cortical tissue and cultured as previously described (Weber et al., 2016). Briefly, kidney cortical tissue was diced and subsequently incubated under agitation for $30 \mathrm{~min}$ at $37^{\circ} \mathrm{C}$ in a $1 \mathrm{mg} / \mathrm{ml}$ solution of collagenase type IV in Hank's balanced salt solution. The free cell-containing supernatant was then transferred to new conical tubes and washed with PTEC culture medium (DMEM/F12 medium supplemented with insulin, transferrin, selenium, penicillin, streptomycin, amphotericin $\mathrm{B}$, and $50 \mathrm{nM}$ hydrocortisone). The cell suspension was centrifuged at $200 \mathrm{~g}$ for $5 \mathrm{~min}$ and the supernatant was aspirated. The cell pellet was then resuspended in PTEC culture medium and transferred to tissue culture flasks. Cell culture medium was replaced after

Abbreviations

1a,25(OH $)_{2} D_{3}, 1 a, 25$-dihydroxyvitamin $\mathrm{D}_{3} ; 24,25(\mathrm{OH})_{2} \mathrm{D}_{3}, 24,25$-dihydroxyvitamin $\mathrm{D}_{3} ; 25 \mathrm{OHD}$, 25-hydroxyvitamin $\mathrm{D}_{3}$; CKD, chronic kidney disease; CYP, cytochrome $\mathrm{P} 450$; $\mathrm{DBP}$, vitamin $\mathrm{D}$ binding protein; $E C_{50}$, concentration of inducer at which half-maximal effect occurs; $E_{\max }$, predicted maximal inductive effect; FBS, fetal bovine serum; PTECs, proximal tubule epithelial cells; PT-MPS, proximal tubule microphysiological system; RAP, receptor-associated protein; VDR, vitamin D receptor 
$24 \mathrm{~h}$ and then every $3 \mathrm{~d}$ thereafter. Cells were expanded and subcultured in tissue culture treated flasks. Cell detachment was performed using $0.05 \%$ trypsin with EDTA and DMEM/F12 medium containing 10\% FBS was used for enzymatic quenching. For use in experiments, PTECs (passage 1-5) were either seeded into well plates, Transwell ${ }^{\circledR}$ inserts or single-channel Nortis microfluidic tubules to constitute a proximal tubule microphysiological system (PT-MPS). Cells cultured in all platforms were maintained under previously established "standard" cell culture conditions of $5 \% \mathrm{CO}_{2}, 37^{\circ} \mathrm{C}$ and PTEC culture medium (Weber et al., 2016). Cells cultured in the PT-MPS were perfused with medium at a rate of $0.5 \mu \mathrm{l} / \mathrm{min}$.

\section{Statistical analysis}

All statistical analyses were conducted using GraphPad Prism version 5.04 (GraphPad Software, La Jolla, CA). Data in figures depicts the mean \pm SEM. All statistical tests evaluating "fold-changes" in the data (i.e., ratios) utilized log-transformed data to ensure parity between fold-reductions and fold-increases. Whenever possible, data was paired by kidney tissue donor. This paired comparison of log-transformed ratios is referred to throughout this paper as a ratio t-test. Statistically significant results are marked with *, p $<0.05$ and $* *, p<0.01$.

\section{Megalin localization in cultured human PTECs}

Because validated commercially-available antibodies for megalin require heat-mediated antigen retrieval, and the MPS platform currently does not permit this technique, we performed immunocytochemical staining for megalin protein localization in 2-dimensional Transwell ${ }^{\circledR}$ cell culture inserts. Briefly, PTECs were seeded at a density of $2 \times 10^{5}$ cells onto collagen IV-coated transparent Transwell ${ }^{\circledR}$ inserts and allowed to attach for $5 \mathrm{~h}$. Medium was then removed from the inserts and replaced with medium containing $0.25 \mathrm{mg} / \mathrm{ml} \mathrm{Matrigel}{ }^{\circledR}$ and left overnight. The next day, the medium was replaced with medium without Matrigel ${ }^{\circledR}$ and the cells were cultured further under standard conditions. After 7 days, the cells were fixed in a solution of $4 \%$ formaldehyde and $2 \%$ sucrose for $10 \mathrm{~min}$. They were then incubated in $50 \mathrm{mM}$ ammonium chloride for $30 \mathrm{~min}$ and rinsed 3 times with DPBS ${ }^{++}$. Next, cells were incubated in a solution of $0.05 \%$ Tween-20 in $10 \mathrm{mM}$ sodium citrate buffer $(\mathrm{pH}=6)$ for $20 \mathrm{~min}$ at $100^{\circ} \mathrm{C}$. Cells were allowed to cool to room temperature (RT) before being blocked with PTB (a solution of $0.1 \%$ Triton $\mathrm{X}-100$ and $5 \%$ bovine serum albumin in $\mathrm{DPBS}^{++}$) for $30 \mathrm{~min}$. Rabbit anti-megalin and mouse anti-sodium-potassium ATPase primary antibodies in PTB were added to the inserts and incubated at RT for $30 \mathrm{~min}$. Controls for non-specific binding of secondary antibodies were simultaneously incubated with PTB in the absence of primary antibodies. Information on primary antibodies is provided in Table $\mathrm{S}^{1}{ }^{1}$. The inserts were washed three times with $\mathrm{DPBS}^{++}$, and the cells were then incubated with a 1:1000 dilution of both Alexa Fluor 594 conju-

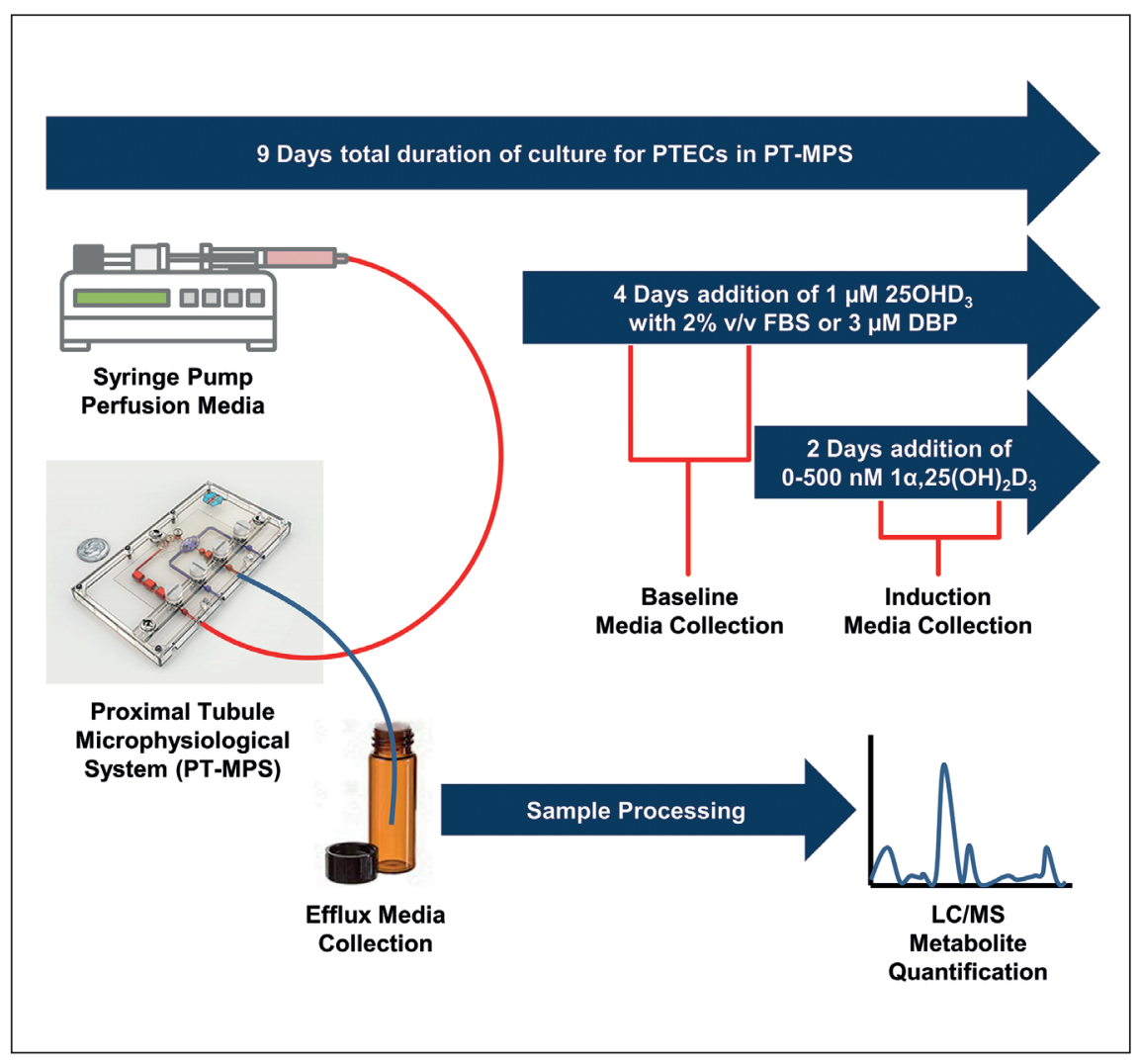

1 doi:10.14573/altex.1803161s
Fig. 1: General scheme for experiments evaluating dose-dependent regulation of CYP24A1 by $1 \alpha, 25(\mathrm{OH})_{2} \mathrm{D}_{3}$ in the PT-MPS PT-MPS are perfused with medium containing $1 \mu \mathrm{M} 25 \mathrm{OHD}_{3}$ for $48 \mathrm{~h}$ with either $2 \%$ FBS or $3 \mu \mathrm{M}$ DBP serving as a carrier vehicle for vitamin D metabolites. Baseline $24,25(\mathrm{OH})_{2} \mathrm{D}_{3}$ formation clearance is determined for each PTMPS from metabolite concentrations in the medium exiting the PT-MPS during the 24 to 48-h period of the "baseline" phase. The various PT-MPS then receive a range of $1 \alpha, 25(\mathrm{OH})_{2} \mathrm{D}_{3}$ concentrations or vehicle control for the subsequent $48 \mathrm{~h}$. The CYP24A1 substrate $\left(1 \mu \mathrm{M} 25 \mathrm{OHD}_{3}\right)$ and the respective carrier protein source (FBS or DBP) for each PT-MPS is continued throughout the "induction" phase. The $24,25(\mathrm{OH})_{2} \mathrm{D}_{3}$ formation clearance during the "induction" phase is determined from the efflux medium of each PT-MPS during hours 24 to 48 of the 2-day collection interval following the initiation of $1 \alpha, 25(\mathrm{OH})_{2} \mathrm{D}_{3}$ co-treatment. Fold-increase in $24,25(\mathrm{OH})_{2} \mathrm{D}_{3}$ formation clearance from the baseline to the induced state is calculated for each PT-MPS receiving $1 \alpha, 25(\mathrm{OH})_{2} \mathrm{D}_{3}$ and standardized as a percentage increase in $24,25(\mathrm{OH})_{2} \mathrm{D}_{3}$ formation clearance over the vehicle control. 
gated donkey anti-mouse IgG and Alexa Fluor 488 conjugated donkey anti-rabbit IgG for $30 \mathrm{~min}$ at RT. The cells were rinsed 3 times with $\mathrm{DPBS}^{++}$, and exposed to a 30-min incubation with a 1:3 dilution of 4',6-diamidino-2-phenylindole (DAPI) in $\mathrm{DPBS}^{++}$. The cells were again rinsed 3 times with $\mathrm{DPBS}^{++}$before the porous membrane of the cell culture insert was extracted using a scalpel and tweezers. The membrane was mounted in deionized water on glass microscope slides and imaged using a Zeiss LSM 780 confocal microscope (Carl Zeiss, Oberkochen, Germany). Confocal images were processed in Velocity software version 6.3 from PerkinElmer (Waltham, MA).

Comparison of the effects of DBP and FBS on

the $1 \alpha, 25(\mathrm{OH})_{2} \mathrm{D}_{3}$-mediated regulation of $\mathrm{CYP} 24 \mathrm{Al}$

enzymatic activity in the PT-MPS

Having confirmed the suitability of purified human DBP as a delivery vehicle for vitamin D metabolites (See Fig. S1 ${ }^{1}$ ), we conducted an exploratory experiment (outlined in Fig. 1) with a single donor comparing the relative effects of the two delivery vehicles (FBS and DBP) on the $1 \alpha, 25(\mathrm{OH})_{2} \mathrm{D}_{3}$-mediated induction of 24-hydroxylation activity. Human PTECs from a single donor were cultured in the PT-MPS for 5 days post seeding, as described. All PT-MPS received $1 \mu \mathrm{M} 25 \mathrm{OHD}_{3}$ for $48 \mathrm{~h}$. Using Equation 1 , baseline $24,25(\mathrm{OH})_{2} \mathrm{D}_{3}$ formation clearance $\left(C L_{f}\right)$ was determined for each PT-MPS from metabolite concentrations in the medium exiting the PT-MPS during hours 24 to 48 of the 2-day collection interval, following the addition of $25 \mathrm{OHD}_{3}$ to the perfusion medium.

$$
C L_{f}=\frac{\text { Net Effluent Appearance Rate }}{24,25(\mathrm{OH})_{2} D_{3}}
$$

In order to assess dose-dependency in the VDR-mediated induction of CYP24A1 expression and activity, the 16 tubules were randomly assigned to groups of 4 to receive either 500, 100, $10 \mathrm{nM}$ of the VDR ligand, $1 \alpha, 25(\mathrm{OH})_{2} \mathrm{D}_{3}$, or $0.1 \%$ ethanol vehicle control for the subsequent $48 \mathrm{~h}$. The CYP24A1 substrate, $1 \mu \mathrm{M} 25 \mathrm{OHD}_{3}$, was also continued in all PT-MPS throughout the treatment phase. The $24,25(\mathrm{OH})_{2} \mathrm{D}_{3}$ formation clearance during the "induction" phase was determined from medium exiting each PT-MPS during hours 24 to 48 of the 2-day collection interval following the initiation of $1 \alpha 25(\mathrm{OH})_{2} \mathrm{D}_{3}$ induction. The experiment was conducted with either $2 \%$ FBS or $3 \mu \mathrm{M}$ DBP serving as the carrier vehicle for vitamin D metabolites. Fold-increase in $C L_{f}$ from the baseline $\left(C L_{f \text { (baseline phase,treatment })}\right)$ to the induced state $\left(C L_{f}\right.$ (baseline phase,treatment) $)$ was calculated for each PT-MPS and standardized to the fold-change in $C L_{f}$ from the baseline $C L_{f}$ (baseline phase,treatment) $)$ to the "induction" phase $C L_{f(\text { baseline phase,treat- }}$ ment)) of the vehicle control (Equation 2).

$$
\% \text { Increase }=\left\{\left(\frac{C L_{f(\text { induction phase,treatment) }}}{C L_{f(\text { baseline phase,treatment })}} / \frac{C L_{f(\text { induction phase,vehicle })}}{C L_{f(\text { baseline phase,vehicle })}}\right)-1\right\} \times 100 \%
$$

The parameters of maximal induction $\left(E_{\max }\right)$ and the concentration of $1 \alpha, 25(\mathrm{OH})_{2} \mathrm{D}_{3}$ at which half maximal induction is observed $\left(E C_{50}\right)$ were then estimated using the simple $E_{\text {max }}$ model, outlined in Equation 3.

$$
\% \text { Increase }=\frac{E_{\max } \times\left[1 \alpha 25(\mathrm{OH})_{2} D_{3}\right]}{E C_{50}+\left[1 \alpha 25(\mathrm{OH})_{2} D_{3}\right]}
$$

The estimated $E_{\max }$ and $E C_{50}$ for the dose-dependent induction of 24-hydroxylation activity was then visually compared between PT-MPS supplemented with FBS versus DBP.

Evaluation of the effects of megalin inhibition on the cellular uptake and 24-hydroxylation of $25 \mathrm{OHD}_{3}$ in the PT-MPS

PT-MPS were cultured under standard conditions (16-20 PT-MPS per donor) for 5 days. Then PT-MPS were perfused $(0.5 \mu \mathrm{l} / \mathrm{min})$ for $48 \mathrm{~h}$ with $3 \mu \mathrm{M}$ DBP-supplemented medium containing $500 \mathrm{nM}$ $1 \alpha, 25(\mathrm{OH})_{2} \mathrm{D}_{3}$. This 48 -h pre-incubation of $1 \alpha, 25(\mathrm{OH})_{2} \mathrm{D}_{3}$ was employed to induce $C Y P 24 A 1$ activity and enhance sensitivity to quantify the 24-hydroxylation of the relatively lower $25 \mathrm{OHD}_{3}$ concentrations. In order to remove residual $1 \alpha, 25(\mathrm{OH})_{2} \mathrm{D}_{3}$ and promote the equilibration of incoming vitamin $\mathrm{D}$ metabolites, an $8 \mathrm{~h}$ accelerated perfusion $(2.5 \mu \mathrm{l} / \mathrm{min})$ of DBP-supplemented medium without $1 \alpha, 25(\mathrm{OH})_{2} \mathrm{D}_{3}$, but containing different $25 \mathrm{OHD}_{3}$ concentrations (ranging from 0.25 to $3 \mu \mathrm{M}$ ), was administered to the PT-MPS. Perfusion with $25 \mathrm{OHD}_{3}$ in the DBP-supplemented medium was then reduced to $0.5 \mu \mathrm{l} / \mathrm{min}$ and a specific inhibitor of receptor-mediated (e.g., megalin-mediated) endocytosis $(1 \mu \mathrm{M}$ RAP - receptor associated protein) was administered to half of the PT-MPS at each $25 \mathrm{OHD}_{3}$ concentration (Niemeier et al., 1999; Rowling et al., 2006). Medium was collected for 1 day and concentrations of $25 \mathrm{OHD}_{3}$ and $24,25(\mathrm{OH})_{2} \mathrm{D}_{3}$ were determined using a previously established LC-MS/MS method (Wang et al., 2011; Weber et al., 2016). The disappearance rate of $25 \mathrm{OHD}_{3}$ from the perfusion medium was calculated according to Equation 4.

$25 \mathrm{OHD}_{3}$ Disappearance Rate $=\frac{[25 \mathrm{OHD}]_{\text {input }}-[25 \mathrm{OHD}]_{3} \text { outflow }}{\text { Duration of Collection Interval } / \text { Volume Collected }}$

The net appearance rate for $24,25(\mathrm{OH})_{2} \mathrm{D}_{3}$ was also calculated across the range of $25 \mathrm{OHD}_{3}$ input concentrations (see Equation $\mathrm{S}^{1}$ ). Given the roughly proportional increase in both $24,25(\mathrm{OH})_{2} \mathrm{D}_{3}$ net appearance and $25 \mathrm{OHD}_{3}$ disappearance rate across the range of $25 \mathrm{OHD}_{3}$ input concentrations, a simple linear regression model was fit to the data. Under these linear conditions, the slope of the $24,25(\mathrm{OH})_{2} \mathrm{D}_{3}$ net appearance and $25 \mathrm{OHD}_{3}$ disappearance rate across the concentration reflects the intrinsic clearance of $24,25(\mathrm{OH})_{2} \mathrm{D}_{3}$ appearance $\left(C L_{\text {int, } 24,25(\mathrm{OH}) 2 \mathrm{D} 3}\right)$ and $25 \mathrm{OHD}_{3}$ disappearance $\left(\mathrm{CL}_{\text {int }}, 24,25(\mathrm{OH}) 2 \mathrm{D} 3\right)$, respectively. The effect of RAP on each intrinsic clearance was evaluated using ratio t-tests paired by kidney tissue donor $(n=5$ biological replicates, all from male donors). Insufficient numbers of female donors yielding viable cells and the small sample size precluded an assessment of potential sex-dependent effects of RAP on the variables of interest. De-identified subject information for each kidney tissue donor is provided in Table $\mathrm{S} 2^{1}$.

\section{Effect of megalin inhibition on $1 \alpha, 25(\mathrm{OH})_{2} \mathrm{D}_{3}$-mediated} induction of CYP24A1 enzymatic activity in the PT-MPS The experimental design outlined in Figure 1 was modified so that all PT-MPS received $3 \mu \mathrm{M}$ DBP as the carrier protein source. During the induction phase, half of the PT-MPS, per $1 \alpha, 25(\mathrm{OH})_{2} \mathrm{D}_{3}$ concentration, additionally received $1 \mu \mathrm{M}$ RAP. Fold induction of $24,25(\mathrm{OH})_{2} \mathrm{D}_{3}$ formation clearance was calculated as before and compared in the presence and absence of RAP. The experiment was then repeated for a total of 5 donors ( 4 males and 1 female), 
two of which were also evaluated in the presence of $2000 \mathrm{nM}$ $1 \alpha, 25(\mathrm{OH})_{2} \mathrm{D}_{3}$ to confirm that near-maximal induction was likely achieved where $500 \mathrm{nM} 1 \alpha, 25(\mathrm{OH})_{2} \mathrm{D}_{3}$ was the highest evaluated concentration. The shifts in $E C_{50}$ and $E_{\max }$ were then evaluated using a ratio t-test comparing the estimated parameters from each donor in the presence and absence of RAP. Insufficient numbers of female donors yielding viable cells and the small sample size precluded an assessment of sex-dependent effects of RAP on the variables of interest. De-identified subject information for each kidney tissue donor is provided in Table $\mathrm{S} 3^{1}$.

\section{Effect of megalin inhibition on $1 \alpha, 25(\mathrm{OH})_{2} \mathrm{D}_{3}$-mediated induction of CYP24A1 protein accumulation in the PT-MPS}

PT-MPS were maintained for 5 days under standard culture conditions. The culture medium was then supplemented with $3 \mu \mathrm{M}$ human DBP and the cells were treated with either $500 \mathrm{nM} 1 \alpha, 25(\mathrm{OH})_{2} \mathrm{D}_{3}$ in the presence or absence of $1 \mu \mathrm{M}$ RAP or $0.1 \%$ ethanol vehicle control. After 2 days of culture under these treatment conditions, the cells were fixed by flowing a solution of $4 \%$ formaldehyde and $2 \%$ D-sucrose in $\mathrm{DPBS}^{++}$at $10 \mu \mathrm{l} / \mathrm{min}$ through the PT-MPS for $20 \mathrm{~min}$. Using a previously established method (Weber et al., 2016), staining was conducted with a 1:200 dilution of goat anti-CYP24A1 and a 1:1000 dilution of Alexa Fluor 488 conjugated donkey anti-goat IgG (secondary antibody). Information on primary antibodies is provided in $\mathrm{Ta}-$ ble $\mathrm{S}^{1}{ }^{1}$. Control PT-MPS tubules were perfused with secondary antibody in the absence of primary antibody pre-incubation in order to assess non-specific binding of the secondary antibody. Images of the PT-MPS tubules were captured on a Nikon Eclipse Ti fluorescent microscope (Melville, NY).

\section{Characterization of the effects of $1 \alpha, 25(\mathrm{OH})_{2} \mathrm{D}_{3}$ on megalin gene expression}

In order to increase total mRNA yield and improve sensitivity for megalin gene expression, human PTECs were cultured in collagen IV-coated 6-well plates, rather than the PT-MPS. The cells were cultured under standard conditions for 5 days before being exposed to a range of concentrations (0-500 $\mathrm{nM})$ of $1 \alpha, 25(\mathrm{OH})_{2} \mathrm{D}_{3}$. After $24 \mathrm{~h}$ exposure, the cells were homogenized in $1 \mathrm{ml}$ of $\mathrm{TRIzol}^{\circledR}$ reagent. The samples were collected and stored at $-80^{\circ} \mathrm{C}$ until processing and analysis. The mRNA was then isolated according to the TRIzol ${ }^{\circledR}$ manufacturer-supplied protocol and quantified on a NanoDrop ND-2000 spectrophotometer from Thermo-Fisher (Waltham, MA). Isolated RNA was mixed with other components of the high-capacity cDNA reverse transcription kit according to the manufacturer-supplied protocol. Reverse transcription was conducted in a PTC-200 thermal cycler (Bio-Rad, Hercules, $\mathrm{CA}$ ) under the following conditions: $10 \mathrm{~min}$ at $25^{\circ} \mathrm{C}, 120 \mathrm{~min}$ at $37^{\circ} \mathrm{C}$, and $5 \mathrm{sec}$ at $85^{\circ} \mathrm{C}$. Quantitative real-time polymerase chain reactions were then performed under the following conditions: warm up at $50^{\circ} \mathrm{C}$ for $10: 00$, followed by 40 cycles of $95^{\circ} \mathrm{C}$ for $5: 10$, and $60^{\circ} \mathrm{C}$ for $0: 30$. TaqMan gene expression assays were used to evaluate the dose-dependent effects of $1 \alpha, 25(\mathrm{OH})_{2} \mathrm{D}_{3}$ on megalin, CYP24A1 (inductive control) and $C Y P 27 B 1$ (suppressive control) gene expression. The $\Delta \Delta \mathrm{Ct}$ method, using glyceraldehyde 3-phosphate dehydrogenase

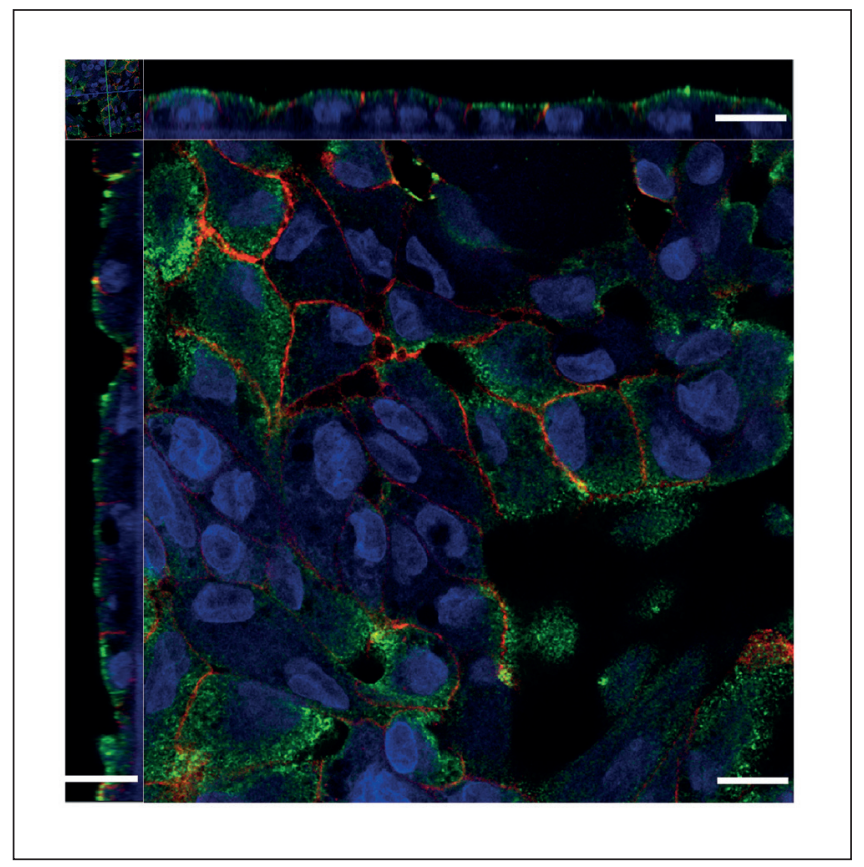

Fig. 2: Megalin protein localization in PTECs

Megalin (green signal) is preferentially expressed along the apical and adjacent subapical regions of cultured human proximal tubule epithelial cells (PTECs), as is seen in vivo. Sodium-potassium ATPase (red signal) was used as a counterstain for the cells' basolateral membranes. Scale bar represents $10 \mu \mathrm{m}$.

$(G A P D H)$ as a housekeeping gene, was employed to quantify relative amounts of megalin (i.e., $L R P 2), C Y P 24 A 1$ and $C Y$ $P 27 B 1$ mRNA transcripts in all samples. A one-way ANOVA, treating different $1 \alpha, 25(\mathrm{OH})_{2} \mathrm{D}_{3}$ doses in a given donor as repeated measures, was performed on the log-transformed data. Post-hoc ratio t-tests ( $\mathrm{n}=6$ biological replicates) between each $1 \alpha, 25(\mathrm{OH})_{2} \mathrm{D}_{3}$ dose and the vehicle control $(0.1 \%$ ethanol $)$ were then conducted for each of the genes evaluated (megalin, CYP24A1 and CYP27B1). Levels of CYP24A1 RNA were below the limit of quantification in the vehicle control group, so the group was omitted from the statistical analysis. Post-hoc t-tests for CYP24A1 compared gene expression in cells treated with $1 \mathrm{nM} 1 \alpha, 25(\mathrm{OH})_{2} \mathrm{D}_{3}$ (rather than vehicle control) to those treated with higher doses.

\section{Results}

\subsection{Megalin localization in cultured human PTECs}

Megalin was expressed along the apical and adjacent subapical regions of cultured human PTECs (Fig. 2). Sodium-potassium ATPase served as a counterstain for cell basolateral membranes (Molitoris et al., 1992; Secker et al., 2017). Proper expression and cellular localization of megalin confirmed the suitability of our in vitro system for studying megalin-mediated luminal reuptake of vitamin D metabolites. 


\subsection{DBP and FBS differentially affect the regulation of CYP24A 1 activity by $1 a, 25(\mathrm{OH})_{2} \mathrm{D}_{3}$}

DBP is considered essential for megalin-mediated uptake of $25 \mathrm{OHD}_{3}$ (Nykjaer et al., 1999). Thus, the switch to purified human DBP from the previously established delivery vehicle, fetal bovine serum (FBS) (Weber et al., 2016), represents an improvement in facilitating a more controlled megalin-dependent delivery of vitamin D metabolites. In order to validate the use of DBP as a delivery vehicle, we first confirmed the successful uptake and metabolism of $25 \mathrm{OHD}_{3}$ to the PT-MPS in the presence of purified DBP (Fig. S1 ${ }^{1}$ ). Next, we compared the relative effects of DBP and FBS on $1 \alpha, 25(\mathrm{OH})_{2} \mathrm{D}_{3}$-mediated induction of CYP24Al activity in the PT-MPS. Co-administration of $25 \mathrm{OHD}_{3}$ and a range of $1 \alpha, 25(\mathrm{OH})_{2} \mathrm{D}_{3}$ concentrations resulted in a dose-dependent increase in the appearance of $24,25(\mathrm{OH})_{2} \mathrm{D}_{3}$ in the efflux of both DBP- and FBS-supplemented perfusion media (Fig. 3). The maximal induction $\left(E_{\max }\right)$ of $24,25(\mathrm{OH})_{2} \mathrm{D}_{3}$ formation clearance in DBP-supplemented medium was over 40-fold greater than the baseline activity and approximately 10-fold greater than the increase with FBS. Based on these results and given their physiological relevance, the remaining experiments were conducted using DBP for the delivery of vitamin D metabolites.

\subsection{RAP inhibits cellular uptake of DBP-bound 25OHD}

PT-MPS were perfused with $25 \mathrm{OHD}_{3} \pm \mathrm{RAP}$. Both the rate of $24,25(\mathrm{OH})_{2} \mathrm{D}_{3}$ formation (Fig. 4) and the loss of $25 \mathrm{OHD}_{3}$ (Fig. 5 ) from the perfusion medium increased proportionally with measured $25 \mathrm{OHD}_{3}$ input concentrations. Co-administration of RAP resulted in a significant 2.4-fold reduction in the intrinsic clearance of $25 \mathrm{OHD}_{3}\left(\mathrm{CL}_{\text {int }}, 25 \mathrm{OHD} 3\right)$ from the perfusion medium, confirming a role of megalin in the uptake of DBP-bound $25 \mathrm{OHD}_{3}$ in human PTECs. Because $1 \mu \mathrm{M}$ RAP fully, but selectively, inhibits binding of DBP to megalin and the megalin-dependent co-receptor cubilin (Niemeier et al., 1999; Rowling et al., 2006), other non-receptor mediated endocytotic processes, as well as passive diffusion across the PTEC apical membranes, may account for the residual uptake of $25 \mathrm{OHD}_{3}$ into the PTECs observed during RAP co-administration. The experiment was not designed to specifically identify the relative contributions of these residual uptake processes. Finally, megalin inhibition had no effect on the appearance of $24,25(\mathrm{OH})_{2} \mathrm{D}_{3}$ in the perfusion medium (Tab. 1), suggesting the intracellular fate of endocytosed $25 \mathrm{OHD}_{3}$ to be complex.

\subsection{Megalin inhibition impairs $1 \mathrm{a}, 25(\mathrm{OH})_{2} \mathrm{D}_{3}$ - mediated induction of CYP24A1}

Bioactive $1 \alpha, 25(\mathrm{OH})_{2} \mathrm{D}_{3}$ circulates tightly bound to DBP(Bikle et al., 1985), but the role of megalin in its delivery to the renal proximal tubule has thus far not been evaluated. We assessed whether megalin-mediated uptake of DBP-bound $1 \alpha, 25(\mathrm{OH})_{2} \mathrm{D}_{3}$ modulates the intracellular availability of $1 \alpha, 25(\mathrm{OH})_{2} \mathrm{D}_{3}$ for VDR-dependent biological activity (e.g., induction of CYP24A1-mediated 24-hydroxylation of $25 \mathrm{OHD}_{3}$ ). First, PT-MPS were perfused with $25 \mathrm{OHD}_{3}$ and a baseline value of $24,25(\mathrm{OH})_{2} \mathrm{D}_{3}$ formation clearance was determined. Then, varying concentrations of

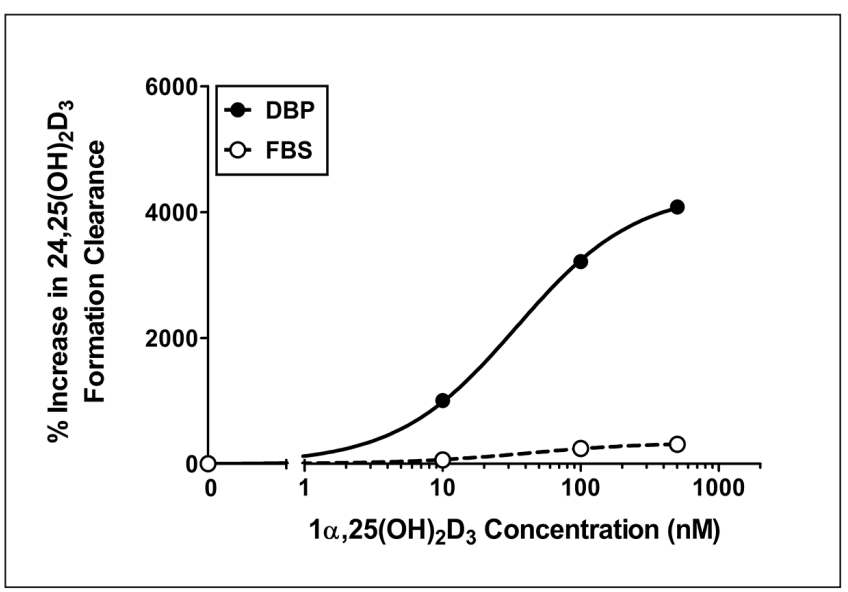

Fig. 3: Relative effects of DBP and FBS on $1 \alpha, 25(\mathrm{OH})_{2} \mathrm{D}_{3}-$ mediated regulation of CYP24A1 activity in the PT-MPS Co-incubation of $25 \mathrm{OHD}_{3}$ and $1 \alpha, 25(\mathrm{OH})_{2} \mathrm{D}_{3}$ across a range (0-500 nM) of concentrations resulted in a dose-dependent increase in the appearance of $24,25(\mathrm{OH})_{2} \mathrm{D}_{3}$ in the efflux of both DBP- and FBS-supplemented perfusion media. The maximal induction $\left(E_{\max }\right)$ of $24,25(\mathrm{OH})_{2} \mathrm{D}_{3}$ formation clearance in DBPsupplemented medium was greater than that seen with FBS coincubation.

$1 \alpha, 25(\mathrm{OH})_{2} \mathrm{D}_{3} \pm \mathrm{RAP}$ were added to the perfusion medium and the increase in the formation of $24,25(\mathrm{OH})_{2} \mathrm{D}_{3}$ was calculated. The mean $1 \alpha, 25(\mathrm{OH})_{2} \mathrm{D}_{3}$ concentration required for half-maximal $\left(E C_{50}\right)$ induction of $24,25(\mathrm{OH})_{2} \mathrm{D}_{3}$ formation displayed a non-significant 1.5 -fold rightward shift upon RAP co-treatment (Fig. 6). More importantly, inhibition of megalin resulted in a significant 1.8 -fold downward shift in the $E_{\max }$ (Tab. 2). This phenomenon was explained by the partial reversal of the $1 \alpha, 25(\mathrm{OH})_{2} \mathrm{D}_{3}$-mediated increase in CYP24A1 protein levels upon RAP co-administration (Fig. 7). The extent of reversibility was moderate but consistent with the analogous moderate reductions in the enzymatic activity data. Given the nature of RAP as an inhibitor of megalin-mediated processes, the presence of other non-receptor mediated endocytotic processes and passive diffusion across the PTEC apical membranes may account for the incomplete suppression of $1 \alpha, 25(\mathrm{OH})_{2} \mathrm{D}_{3}$-mediated induction of CYP24A1 observed during RAP co-administration. While the endpoint for the experiment was fold-induction in the 24-hydroxylation of $25 \mathrm{OHD}_{3}$, a similar fold-increase in 24-hydroxylation of $1 \alpha, 25(\mathrm{OH})_{2} \mathrm{D}_{3}$ would be expected given that CYP24A1 is the only enzyme capable of catalyzing hydroxylation at the 24 position for either substrate and the $1 \alpha, 25(\mathrm{OH})_{2} \mathrm{D}_{3}$-mediated induction of enzymatic activity would be proportional to increases in CYP24A1 protein expression for either substrate.

\section{$3.51 \mathrm{a}, 25(\mathrm{OH})_{2} \mathrm{D}_{3}$ suppresses megalin gene expression in PTECs}

We investigated whether megalin gene expression in human PTECs is regulated by $1 \alpha, 25(\mathrm{OH})_{2} \mathrm{D}_{3}$, as has been observed in rat PTECs (Liu et al., 1998). As shown in Figure $8 \mathrm{~A}$, both megalin and CYP27B1 mRNA were not induced by 

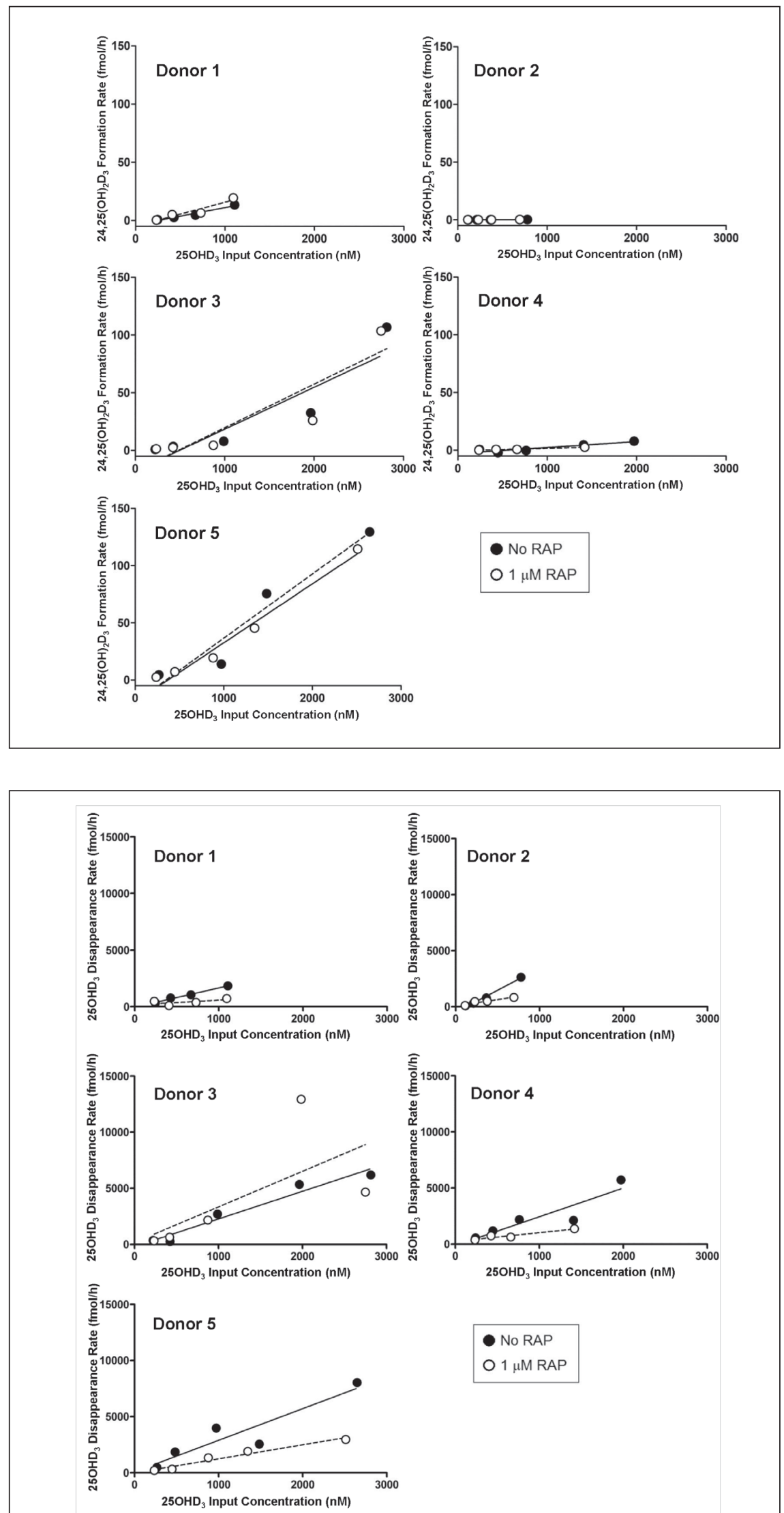

Fig. 4: Megalin inhibition does not affect the formation of $24,25(\mathrm{OH})_{2} \mathrm{D}_{3}$ from $25 \mathrm{OHD}_{3}$ in the PT-MPS

The rate of formation of $24,25(\mathrm{OH})_{2} \mathrm{D}_{3}$ from $25 \mathrm{OHD}_{3}$ was observed to be roughly proportional to the $25 \mathrm{OHD}_{3}$ input concentrations across the measured range of input concentrations tested. There was no significant effect of RAP on the estimated intrinsic formation clearance of $24,25(\mathrm{OH})_{2} \mathrm{D}_{3}$ from $25 \mathrm{OHD}_{3}$.

Fig. 5: Megalin-mediated cellular uptake and loss of DBP-bound $25 \mathrm{OHD}_{3}$ in the PT-MPS

The rate of loss of $25 \mathrm{OHD}_{3}$ from the perfusion medium was observed to be roughly proportional to the $25 \mathrm{OHD}_{3}$ input concentrations across the measured range of input concentrations tested. RAP significantly reduced the estimated intrinsic clearance, reflected in the slope of the linear regression line, of $25 \mathrm{OHD}_{3}$ from the luminal perfusion medium. 
Tab. 1: Donor-specific effects of RAP on the intrinsic clearances of $24,25(\mathrm{OH}))_{2} \mathrm{D}_{3}$ formation and $25 \mathrm{OHD} \mathrm{L}_{3}$ loss Treatment with the megalin inhibitor (RAP) significantly reduced the intrinsic clearance for $25 \mathrm{OHD}_{3}$ loss $\left(\mathrm{CL}_{\text {int, }} 25 \mathrm{OHD3}\right)$ to PTECs cultured in the PT-MPS but had no significant effect on the intrinsic clearance of $24,25(\mathrm{OH})_{2} \mathrm{D}_{3}$ formation $\left(\mathrm{CL}_{\text {int, } 24,25(\mathrm{OH}) 2 \mathrm{D} 3}\right)$.

\begin{tabular}{|c|c|c|c|c|c|c|}
\hline \multirow[b]{2}{*}{ Donor No. } & \multicolumn{3}{|c|}{$C L_{i n t, 24,25(\mathrm{OH}) 2 D 3}(\mu \mathrm{l} / \mathrm{h})$} & \multicolumn{3}{|c|}{$C L_{i n t, 25 O H D 3}(\mu \mathrm{l} / \mathrm{h})$} \\
\hline & No RAP & RAP & $\begin{array}{l}\text { Fold-change } \\
C L_{\text {int }}\end{array}$ & No RAP & RAP & $\begin{array}{l}\text { Fold-change } \\
C L_{\text {int }}\end{array}$ \\
\hline 1 & 0.015 & 0.021 & $1.4 \uparrow$ & 1.7 & 0.42 & $4.0 \downarrow$ \\
\hline 2 & 0.00029 & 0.00037 & $1.3 \uparrow$ & 4.0 & 1.1 & $3.6 \downarrow$ \\
\hline 3 & 0.038 & 0.036 & $1.1 \downarrow$ & 2.5 & 3.2 & $1.3 \uparrow$ \\
\hline 4 & 0.0052 & 0.0021 & $2.5 \downarrow$ & 2.6 & 0.78 & $3.3 \downarrow$ \\
\hline 5 & 0.056 & 0.052 & $1.1 \downarrow$ & 2.8 & 1.3 & $2.2 \downarrow$ \\
\hline Meant & 0.023 & 0.022 & $1.1 \downarrow$ & 2.7 & 1.4 & 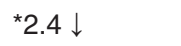 \\
\hline $\mathrm{SD}^{\dagger}$ & 0.024 & 0.022 & 1.6 & 0.83 & 1.1 & 2.0 \\
\hline
\end{tabular}

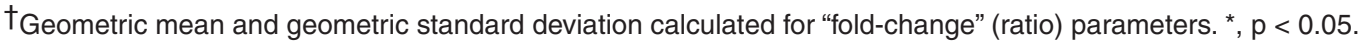

Tab. 2: Donor-specific effects of RAP on $1 \alpha, 25(\mathrm{OH})_{2} \mathrm{D}_{3}$-mediated induction of $24,25(\mathrm{OH})_{2} \mathrm{D}_{3}$ formation clearance

Treatment with the megalin inhibitor (RAP) significantly reduced the maximal inducibility $\left(E_{\text {max }}\right)$ for the $1 \alpha, 25(\mathrm{OH})_{2} \mathrm{D}_{3}-\mathrm{mediated}$ induction of $24,25(\mathrm{OH})_{2} \mathrm{D}_{3}$ formation clearance in the PT-MPS but had no significant effect on the concentration of $1 \alpha, 25(\mathrm{OH})_{2} \mathrm{D}_{3}$ required for halfmaximal induction $\left(E C_{50}\right)$ of $24,25(\mathrm{OH})_{2} \mathrm{D}_{3}$ formation clearance.

\begin{tabular}{|c|c|c|c|c|c|c|}
\hline \multirow[b]{2}{*}{ Donor No. } & \multicolumn{3}{|c|}{$E C_{50}(\mathrm{nM})$} & \multicolumn{3}{|c|}{$E_{\max }(\%$ Increase from baseline) } \\
\hline & No RAP & RAP & $\begin{array}{l}\text { Fold-change } \\
E C_{50}\end{array}$ & No RAP & RAP & $\begin{array}{l}\text { Fold-change } \\
E_{\max }\end{array}$ \\
\hline 1 & 62 & 130 & $2.1 \uparrow$ & 5300 & 3500 & $1.5 \downarrow$ \\
\hline 2 & 25 & 56 & $2.2 \uparrow$ & 990 & 640 & $1.5 \downarrow$ \\
\hline 3 & 5.3 & 170 & $32 \uparrow$ & 800 & 280 & $2.9 \downarrow$ \\
\hline 4 & 240 & 130 & $1.8 \downarrow$ & 5900 & 2300 & $2.6 \downarrow$ \\
\hline 5 & 5.6 & 0.61 & $9.2 \downarrow$ & 235 & 200 & $1.2 \downarrow$ \\
\hline Mean ${ }^{\dagger}$ & 68 & 97 & $1.5 \uparrow$ & 2600 & 1400 & *1.8 $\downarrow$ \\
\hline $\mathrm{SD}^{\dagger}$ & 99 & 68 & 8.1 & 2700 & 1500 & 1.5 \\
\hline
\end{tabular}

†Geometric mean and geometric standard deviation calculated for "fold-change" (ratio) parameters. *, $p<0.05$.

$1 \alpha, 25(\mathrm{OH})_{2} \mathrm{D}_{3}$. Instead, a one-way ANOVA revealed a significant trend of suppression of megalin gene expression by $1 \alpha, 25(\mathrm{OH})_{2} \mathrm{D}_{3}$. Post-hoc ratio t-tests revealed a significant difference between megalin gene expression between the control and $1 \alpha, 25(\mathrm{OH})_{2} \mathrm{D}_{3}$ at the highest $(500 \mathrm{nM})$ dose. Significant up-regulation of the VDR-responsive "inductive" control gene (CYP24A1) was also present (Fig. 8B).

\section{Discussion}

In this study, we observed several key findings: (1) megalin plays a critical role in the delivery of DBP-bound $25 \mathrm{OHD}_{3}$ to the human proximal tubule, (2) megalin-mediated endocytosis of
DBP-bound $1 \alpha, 25(\mathrm{OH})_{2} \mathrm{D}_{3}$ is essential to achieve the maximal physiological response, and (3) elevated $1 \alpha, 25(\mathrm{OH})_{2} \mathrm{D}_{3}$ levels do not induce, and may even suppress, megalin gene expression in human PTECs, contrasting with previously published observations of induction in immortalized rat PTECs (Liu et al., 1998). These results show for the first time in a human cell-derived system the importance of megalin in the uptake of $25 \mathrm{OHD}_{3}$ from glomerular ultrafiltrate and extend that critical function to include the uptake and cellular response to $1 \alpha, 25(\mathrm{OH})_{2} \mathrm{D}_{3}$.

Like $25 \mathrm{OHD}_{3}, 1 \alpha, 25(\mathrm{OH})_{2} \mathrm{D}_{3}$ circulates in the blood tightly bound to DBP (Bikle et al., 1985). Thus, megalin-mediated uptake of DBP-bound $1 \alpha, 25(\mathrm{OH})_{2} \mathrm{D}_{3}$ may permit PTECs to better sense and respond to changes in circulating concentrations of this hormone (Bikle et al., 1985). The effects of megalin 

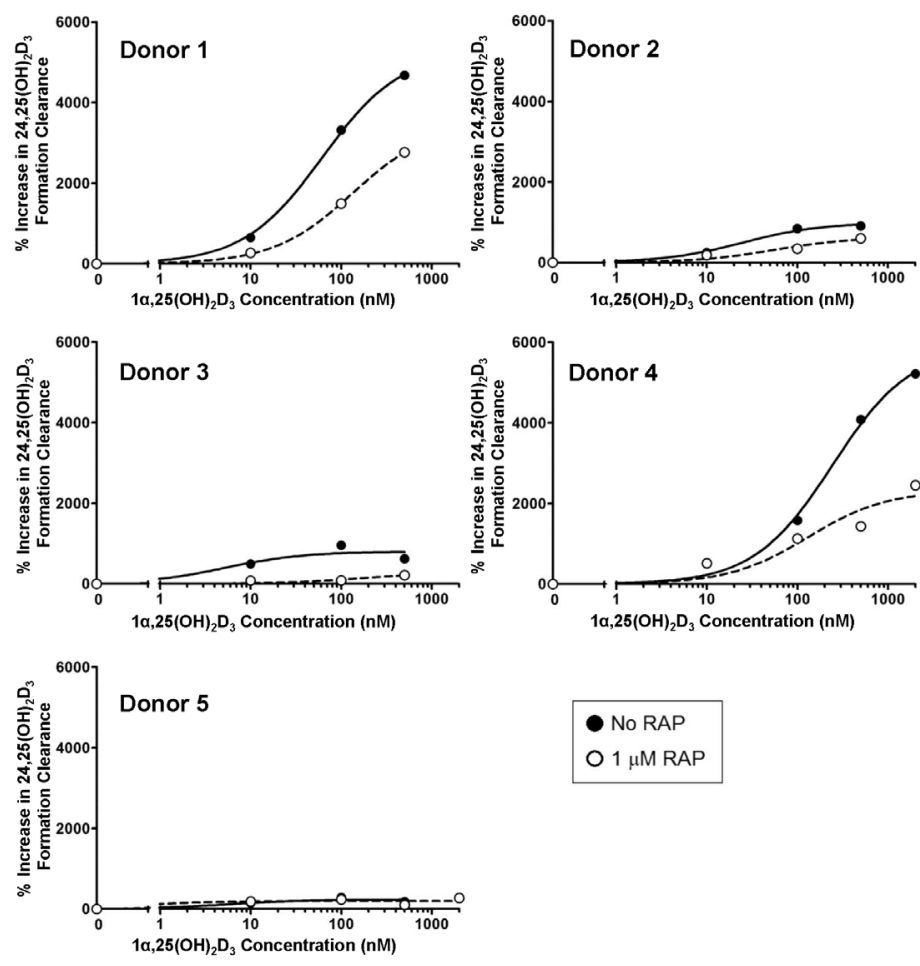

O $1 \mu$ M RAP
Fig. 6: Megalin-mediated uptake of DBP-bound $1 \alpha, 25(\mathrm{OH})_{2} \mathrm{D}_{3}$ is critical for maximal induction of CYP24A1 activity in the PT-MPS The formation of $24,25(\mathrm{OH})_{2} \mathrm{D}_{3}$ from $25 \mathrm{OHD}_{3}$ increased with increasing concentrations of $1 \alpha, 25(\mathrm{OH})_{2} \mathrm{D}_{3}$. Co-incubation with RAP resulted in a statistically significant downward shift in the maximal inductive response $\left(E_{\max }\right)$ but had no significant effect on the concentration required for half-maximal effect $\left(E C_{50}\right)$.
Fig. 7: Megalin inhibition impairs $1 \alpha, 25(\mathrm{OH})_{2} \mathrm{D}_{3}-$ mediated induction of CYP24A1 protein accumulation in the PT-MPS

Treatment of PTECs in the PT-MPS with $500 \mathrm{nM}$ $1 \alpha, 25(\mathrm{OH})_{2} \mathrm{D}_{3}$ (center) resulted in increases in fluorescent signal for CYP24A1 protein compared to the vehicle control (left). This inductive effect appeared to be partially reversed with RAP coadministration (right). For reference, the approximate diameter of PT-MPS tubules shown above is $120 \mu \mathrm{m}$.

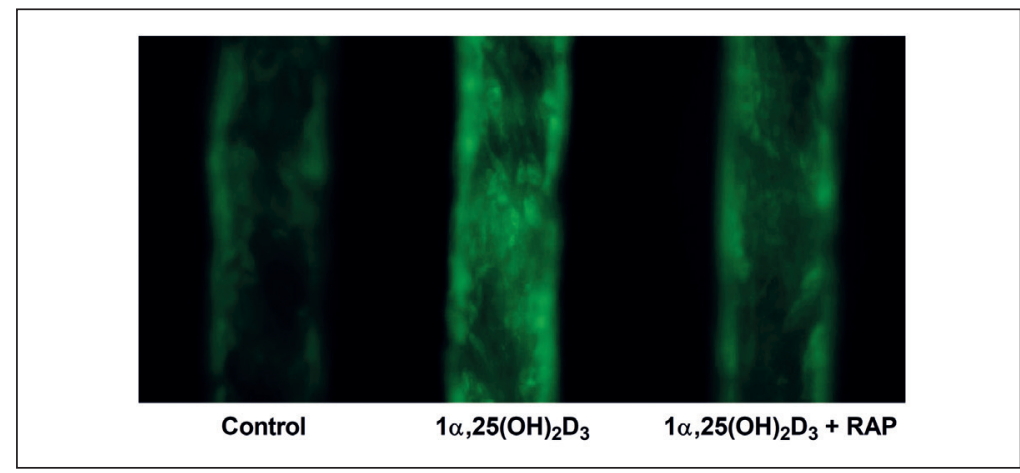

Fig. 8: Comparative effects of $1 \alpha, 25(\mathrm{OH})_{2} D_{3}$ on megalin, CYP24A1 and CYP27B1 gene expression in PTECs

(A) Expression of both megalin and CYP27B1 mRNA expression was suppressed in a roughly dosedependent manner by $1 \alpha, 25(\mathrm{OH})_{2} \mathrm{D}_{3}$. The apparent suppression was statistically significant only for megalin and only at the $500 \mathrm{nM}$ dose.

(B) Upregulation of the VDR-responsive "inductive" control gene (CYP24A1) was observed at both the $100 \mathrm{nM}$ and $500 \mathrm{nM}$ doses of $1 \alpha, 25(\mathrm{OH})_{2} \mathrm{D}_{3}$. Levels of CYP24A1 RNA were below the limit of quantification in the vehicle control group so the group was omitted from the statistical analysis. All gene expression data was standardized to GAPDH. *, $p<0.05 ;{ }^{* *}, p<0.01$.
A

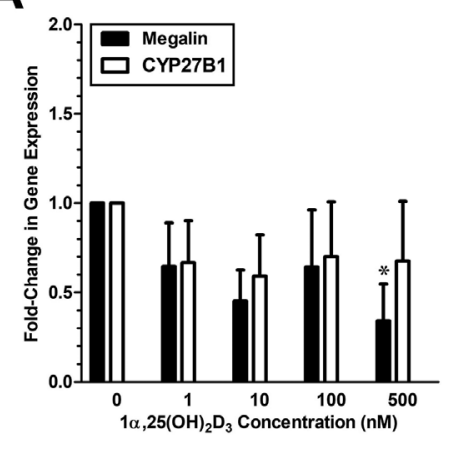

B

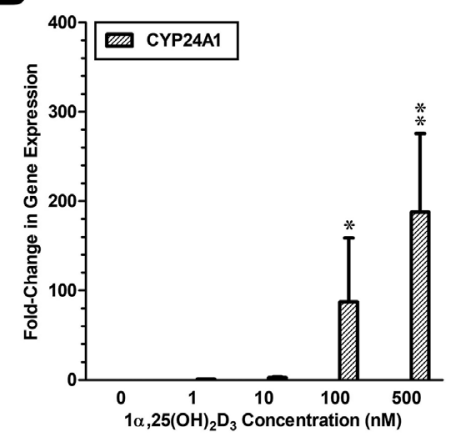




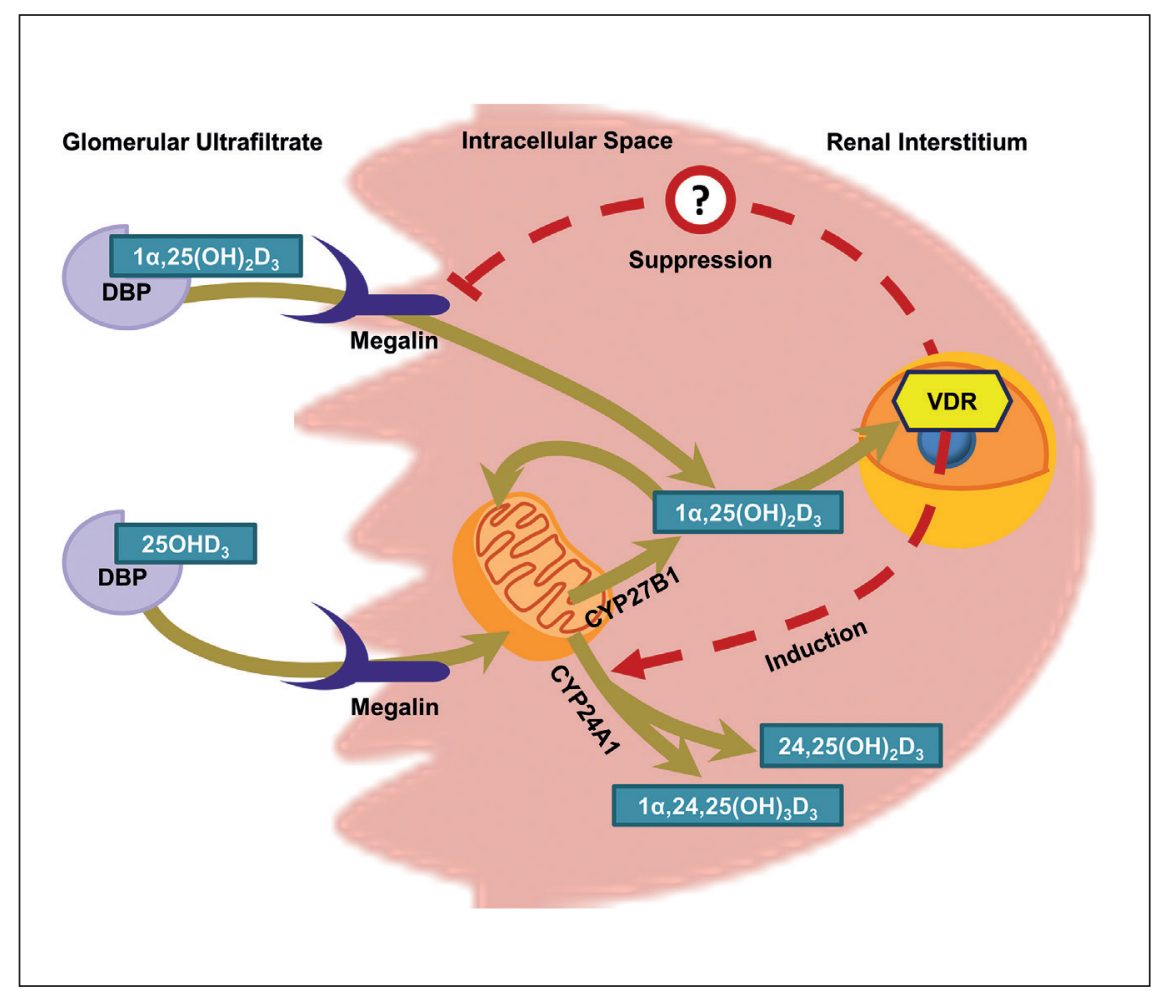

Fig. 9: Role of megalin in the maintenance of renal vitamin $D$ metabolite homeostasis

In PTECs, apically-localized megalin reclaims DBP-bound vitamin D metabolites from the glomerular ultra-filtrate.

Resorbed $25 \mathrm{OHD}_{3}$ is then shuttled to the mitochondria for either CYP24A1-mediated inactivation or CYP27B1-mediated bioactivation. Intracellular $1 \alpha, 25(\mathrm{OH})_{2} \mathrm{D}_{3}$, whether generated within the PTECs mitochondria or resorbed directly from the tubular lumen, can then undergo metabolic inactivation, enter systemic circulation to mediate endocrine effects or exert VDR-dependent intracrine effects within the PTECs. Intracrine effects include the compensatory upregulation of CYP24A1 gene expression. Megalin gene expression may also be a target for $1 \alpha, 25(\mathrm{OH})_{2} \mathrm{D}_{3}$,- $^{-}$ mediated suppression in humans. inhibition on $1 \alpha, 25(\mathrm{OH})_{2} \mathrm{D}_{3}$ hormonal activity manifested predominantly as a reduction in the $E_{\max }$ for $C Y P 24 A 1$ induction, underscoring the importance of DBP in the intracellular trafficking pathways by which endocytosed megalin transfers DBP-bound $1 \alpha, 25(\mathrm{OH})_{2} \mathrm{D}_{3}$ to the intracellular vitamin $\mathrm{D}$ binding proteins (IDBPs) critical in achieving maximal induction of CYP24A1. These conclusions are bolstered by previous observations of direct interactions between IDBPs and megalin (Adams et al., 2003). In particular, IDBP-1 has been shown to bind $1 \alpha, 25(\mathrm{OH})_{2} \mathrm{D}_{3}$ with a high capacity and to translocate to the nucleus where it can facilitate the delivery of bound $1 \alpha, 25(\mathrm{OH})_{2} \mathrm{D}_{3}$ to VDR (Gacad and Adams, 1993, 1998; Adams et al., 2007). Our observations form the basis upon which further trafficking studies can be designed to identify the specific proteins in the megalin-initiated chain of custody that carries the different vitamin D metabolites to their specific intracellular targets.

Taken together, our findings reveal a complex interplay between DBP levels, megalin-mediated uptake, vitamin D bioactivation and the $1 \alpha, 25(\mathrm{OH})_{2} \mathrm{D}_{3}$-mediated induction of its own metabolic inactivation. In order to characterize further homeostatic aspects of this interplay, we investigated whether $1 \alpha, 25(\mathrm{OH})_{2} \mathrm{D}_{3}$ participates in the reciprocal regulation on megalin gene expression. Hereto, the body of literature evaluating the role of $1 \alpha, 25(\mathrm{OH})_{2} \mathrm{D}_{3}$ in megalin regulation has consisted of a sole study in immortalized rat PTECs, which concluded that $1 \alpha, 25(\mathrm{OH})_{2} \mathrm{D}_{3}$ induces the expression of megalin in the human proximal tubule (Liu et al., 1998). The findings of that singular study have served as the basis for a "vicious cycle" hypothesis (Dusso et al., 2011; Dusso, 2011; Kim and Kim, 2014), which states that CKD-related decreases in renal vitamin $\mathrm{D}$ bioactivation can lead to reductions in renal megalin expression (Bosworth and de Boer, 2013), reduce $25 \mathrm{OHD}_{3}$ uptake and biotransformation, and result in a cycle of progressively worsening vitamin D deficiency. Our findings are at odds with this hypothesis and even suggest a hypothesis of compensatory negative feedback, whereby PTECs would compensate for diminishing renal vitamin $\mathrm{D}$ bioactivation by increasing megalin and its resorptive uptake of DBP-bound $25 \mathrm{OHD}_{3}$ into PTECs (Fig. 9). However, with pairwise comparisons, the suppression of megalin gene expression was statistically significant at only $500 \mathrm{nM} 1 \alpha, 25(\mathrm{OH})_{2} \mathrm{D}_{3}$, a superphysiological concentration. However, the previous experiments with immortalized rat PTECs, upon which the "vicious cycle" hypothesis is predicated, were conducted at an even higher (1000 nM) concentration (Liu et al., 1998). These findings call into question the regulation of megalin in the kidney by $1 \alpha, 25(\mathrm{OH})_{2} \mathrm{D}_{3}$ in vivo. That said, negative feedback loops have consistently characterized the physiological regulation of systemic vitamin $\mathrm{D}$ homeostasis (e.g., induction of CYP24A1 and CYP27B1 by $1 \alpha, 25(\mathrm{OH})_{2} \mathrm{D}_{3}$ and parathyroid hormone, respectively) (Jones et al., 2012; Dusso et al., 2005; Brenza et al., 1998). Our findings are more in line with this overarching theme of compensatory regulation and reconcile published results that previously seemed anomalous, such as the down-regulation of megalin gene expression in LLC-PK1 cells exposed to the VDR ligand, lithocholic acid (Erranz et al., 2004). 
In summary, our findings describe megalin as a protein intimately woven into the complex web of physiological mechanisms regulating mineral homeostasis by promoting the uptake of $25 \mathrm{OHD}_{3}$ and $1 \alpha, 25(\mathrm{OH})_{2} \mathrm{D}_{3}$ into human PTECs. Further elucidation of aspects of this regulatory process may provide a better understanding of renal physiology and possibly reveal novel therapeutic targets for CKD. While megalin-knockout mice and rodent cell systems have been useful in the initial identification of megalin as an important regulator of vitamin D homeostasis, concurrent advances in primary human cell culture techniques and microphysiological cell culture platforms now offer promising alternatives to traditional non-human animal models for exploring the many further questions relating to renal vitamin D homeostasis and other important organ functions.

\section{References}

Adams, J. S., Chen, H., Chun, R. F. et al. (2003). Novel regulators of vitamin D action and metabolism: Lessons learned at the Los Angeles zoo. J Cell Biochem 88, 308-314. doi:10.1002/ jcb. 10333

Adams, J. S., Chen, H., Chun, R. et al. (2007). Substrate and enzyme trafficking as a means of regulating 1,25-dihydroxyvitamin D synthesis and action: The human innate immune response. J Bone Miner Res 22, Suppl 2, V20-24. doi:10.1359/ jbmr.07s214

Amsellem, S., Gburek, J., Hamard, G. et al. (2010). Cubilin is essential for albumin reabsorption in the renal proximal tubule. J Am Soc Nephrol 21, 1859-1867. doi:10.1681/ ASN.2010050492

Bikle, D. D., Siiteri, P. K., Ryzen, E. and Haddad, J. G. (1985). Serum protein binding of 1,25-dihydroxyvitamin D: A reevaluation by direct measurement of free metabolite levels. J Clin Endocrinol Metab 61, 969-975. doi:10.1210/ jcem-61-5-969

Bikle, D. D., Gee, E., Halloran, B. et al. (1986). Assessment of the free fraction of 25-hydroxyvitamin $\mathrm{D}$ in serum and its regulation by albumin and the vitamin D-binding protein. J Clin Endocrinol Metab 63, 954-959. doi:10.1210/jcem-63-4-954

Bosworth, C. and de Boer, I. H. (2013). Impaired vitamin D metabolism in CKD. Semin Nephrol 33, 158-168. doi:10.1016/j.semnephrol.2012.12.016

Brenza, H. L., Kimmel-Jehan, C., Jehan, F. et al. (1998). Parathyroid hormone activation of the 25-hydroxyvitamin D31alpha-hydroxylase gene promoter. Proc Natl Acad Sci U S A 95, 1387-1391. doi:10.1073/pnas.95.4.1387

Dusso, A. S., Brown, A. J. and Slatopolsky, E. (2005). Vitamin D. Am J Physiol Renal Physiol 289, F8-28. doi:10.1152/ ajprenal.00336.2004

Dusso, A. S. (2011). Kidney disease and vitamin D levels: 25hydroxyvitamin D, 1,25-dihydroxyvitamin D, and VDR activation. Kidney Int, Suppl 1, 136-141. doi:10.1038/ kisup.2011.30

Dusso, A., Gonzalez, E. A. and Martin, K. J. (2011). Vitamin $\mathrm{D}$ in chronic kidney disease. Best Pract Res Clin Endocrinol Metab 25, 647-655. doi:10.1016/j.beem.2011.05.005
Erranz, B., Miquel, J. F., Argraves, W. S. et al. (2004). Megalin and cubilin expression in gallbladder epithelium and regulation by bile acids. J Lipid Res 45, 2185-2198. doi:10.1194/j1r. M400235-JLR200

Gacad, M. A. and Adams, J. S. (1993). Identification of a competitive binding component in vitamin D-resistant New World primate cells with a low affinity but high capacity for 1,25 dihydroxyvitamin D3. J Bone Miner Res 8, 27-35. doi:10.1002/ jbmr.5650080105

Gacad, M. A. and Adams, J. S. (1998). Proteins in the heat shock-70 family specifically bind 25-hydroxyvitamin D3 and 17beta-estradiol. J Clin Endocrinol Metab 83, 1264-1267. doi:10.1210/jcem.83.4.4725

Jones, G., Prosser, D. E. and Kaufmann, M. (2012). 25-hydroxyvitamin D-24-hydroxylase (CYP24A1): Its important role in the degradation of vitamin D. Arch Biochem Biophys 523, 9-18. doi:10.1016/j.abb.2011.11.003

Kerjaschki, D., Noronha-Blob, L., Sacktor, B. et al. (1984). Microdomains of distinctive glycoprotein composition in the kidney proximal tubule brush border. J Cell Biol 98, 15051513. doi:10.1083/jcb.98.4.1505

Kim, C. S. and Kim, S. W. (2014). Vitamin D and chronic kidney disease. Korean J Intern Med 29, 416-427. doi:10.3904/ kjim.2014.29.4.416

Liu, W., Yu, W. R., Carling, T. et al. (1998). Regulation of gp330/ megalin expression by vitamins A and D. Eur J Clin Invest 28, 100-107. doi:10.1046/j.1365-2362.1998.00253.x

Maiti, A. and Beckman, M. J. (2007). Extracellular calcium is a direct effecter of VDR levels in proximal tubule epithelial cells that counter-balances effects of PTH on renal vitamin D metabolism. J Steroid Biochem Mol Biol 103, 504-508. doi:10.1016/j.jsbmb.2006.11.012

Molitoris, B. A., Dahl, R. and Geerdes, A. (1992). Cytoskeleton disruption and apical redistribution of proximal tubule $\mathrm{Na}^{+}$$\mathrm{K}^{+}$-ATPase during ischemia. Am J Physiol 263, F488-495. doi:10.1152/ajprenal.1992.263.3.F488

Niemeier, A., Willnow, T., Dieplinger, H. et al. (1999). Identification of megalin/gp330 as a receptor for lipoprotein(a) in vitro. Arterioscler Thromb Vasc Biol 19, 552-561. doi:10.1161/01. ATV.19.3.552

Nielsen, R., Christensen, E. I. and Birn, H. (2016). Megalin and cubilin in proximal tubule protein reabsorption: From experimental models to human disease. Kidney Int 89, 58-67. doi:10.1016/j.kint.2015.11.007

Nykjaer, A., Dragun, D., Walther, D. et al. (1999). An endocytic pathway essential for renal uptake and activation of the steroid 25-(OH) vitamin D3. Cell 96, 507-515. doi:10.1016/S00928674(00)80655-8

Nykjaer, A., Fyfe, J. C., Kozyraki, R. et al. (2001). Cubilin dysfunction causes abnormal metabolism of the steroid hormone 25(OH) vitamin D(3). Proc Natl Acad Sci U S A 98, 1389513900. doi:10.1073/pnas.241516998

Perwad, F., Zhang, M. Y., Tenenhouse, H. S. and Portale, A. A. (2007). Fibroblast growth factor 23 impairs phosphorus and vitamin D metabolism in vivo and suppresses 25hydroxyvitamin D-1alpha-hydroxylase expression in vitro. 
Am J Physiol Renal Physiol 293, F1577-1583. doi:10.1152/ ajprenal.00463.2006

Raghavan, V., Rbaibi, Y., Pastor-Soler, N. M. et al. (2014). Shear stress-dependent regulation of apical endocytosis in renal proximal tubule cells mediated by primary cilia. Proc Natl Acad Sci U S A 111, 8506-8511. doi:10.1073/pnas.1402195111

Raghavan, V. and Weisz, O. A. (2015). Flow stimulated endocytosis in the proximal tubule. Curr Opin Nephrol Hypertens 24, 359-365. doi:10.1097/MNH.0000000000000135

Rowling, M. J., Kemmis C. M., Taffany, D. A. et al. (2006). Megalin-mediated endocytosis of vitamin D binding protein correlates with 25-hydroxycholecalciferol actions in human mammary cells. J Nutr 136, 2754-2759. doi:10.1093/jn/ 136.11.2754

Secker, P. F., Luks, L., Schlichenmaier, N. and Dietrich, D. R. (2017). RPTEC/TERT1 cells form highly differentiated tubules when cultured in a 3D matrix. ALTEX 35, 223-234. doi:10.14573/altex.1710181

Sun, J., Hultenby, K., Axelsson, J. et al. (2017). Proximal tubular expression patterns of megalin and cubilin in proteinuric nephropathies. Kidney Int Rep 2, 721-732. doi:10.1016/j. ekir.2017.02.012

Wang, Y., Zhu, J. and DeLuca, H. F. (2015). The vitamin D receptor in the proximal renal tubule is a key regulator of serum 1alpha,25-dihydroxyvitamin D(3). Am J Physiol Endocrinol Metab 308, E201-205. doi:10.1152/ajpendo.00422.2014
Wang, Z., Senn, T., Kalhorn, T. et al. (2011). Simultaneous measurement of plasma vitamin $\mathrm{D}(3)$ metabolites, including 4beta,25-dihydroxyvitamin D(3), using liquid chromatography-tandem mass spectrometry. Anal Biochem 418, 126-133. doi:10.1016/j.ab.2011.06.043

Weber, E. J., Chapron, A., Chapron, B. D. et al. (2016). Development of a microphysiological model of human kidney proximal tubule function. Kidney Int 90, 627-637. doi:10.1016/j. kint.2016.06.011

\section{Conflict of interest}

The authors have no conflicts of interest.

\section{Acknowledgements}

This work was supported in part by grants from the National Institutes of Health: UH3 TR000504 (JH), R01 GM63666 (KET), TL1 RR025016 (BDC), as well as a 5R25 HG007153-04 grant that funds the University of Washington GenOM Project for minority undergraduate students (MCO). It was also supported by the University of Washington Magnuson Predoctoral Fellowship (AC) and the William E. Bradley Predoctoral Fellowship (AC). 